\title{
Analisis Pendapatan Dan Kelayakan Finansial Usaha Jelli Kelapa Pada UMKM Dekla Di Desa Salo Bangkinang Kabupaten Kampar (Studi pada UMKM Dekla)
}

\author{
MURNAWATI ${ }^{1}$, LILI ERTI $^{2}$, TASRIL $^{3}$ \\ 1,2,3 Universitas Lancang Kuning \\ Jln. Yos Sudarso Km 08 Rumbai Telp. (0761) 52581 Fax. (0761) 52581 \\ E-mail : murnawati@unilak.ac.id
}

\begin{abstract}
The agricultural sector can still have the capacity to produce surplus value. The role of coconut in a micro-scale can be assessed by looking at how much dependence of farmers on this commodity, Jelli Coconut Industry is an industrial business that is engaged in the field of snack production, this business is carried out by home industries, the purpose of the coconut jelly business is as a step to empower economic needs. The research objectives to be achieved are: To analyze income and feasibility Jelli Coconut business obtained by MSME Dekla in Salo Bangkinang Village, Kampar Regency. This study uses a descriptive method with a survey approach, using secondary data and primary data from respondents to the objects in question according to the problems and objectives to be answered, and existing data available at MSME Dekla in the village of Salo Bangkinang Kampar Regency. Coconut jelly business is a business that can be considered because this business is a collection of similar companies and can create added value to absorb labor, the results of research on income and feasibility of coconut jelly business in terms of the financial aspects of the method. Investment payback period (PP) is accepted because it has returned 2 years, 08 months, 12 days shorter than estimated. The Net Present Value (NPV) method of investment research is

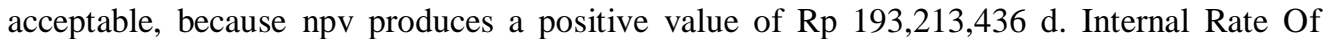
Retun (IRR) The IRR value is obtained at $26.27 \%$ greater than the required profit level of $15 \%$, the IRR is acceptable
\end{abstract}

Keywords: income, feasibility, financial

\begin{tabular}{lll}
\hline Sektor pertanian masih dapat memiliki & dalam dan pendapatan yang berasal \\
kemampan untuk menghasilkan nilai yang & dari usaha di luar pertanian. \\
surplus. Hal ini akan terjadi bila & \multicolumn{1}{c}{ Industri Jelli Kelapa merupakan } \\
produktivitas diperbesar sehingga & usaha industri yang berkesimpung dalam \\
menghasilkan pendapatan yang lebih & $\begin{array}{l}\text { bidang produksi makanan ringan, usaha } \\
\text { besar, dan memungkinkan bisa untuk }\end{array}$ & $\begin{array}{l}\text { ini dilakukan oleh industri rumah tangga, } \\
\text { tujuan usaha jelli kelapa tersebut sebagai }\end{array}$ \\
mengakumulasikan modal. & & $\begin{array}{l}\text { langkah untuk memberdayakan kebutuhan } \\
\text { Pekanan kelapa dalam dari segi }\end{array}$ \\
mikro dapat di kaji dengan melihat berapa & ekonomi
\end{tabular}
besar ketergantungan petani terhadap komoditi ini, dipandang dari aspek pendapatan petani, maka sumber pendapatan petani dapat dikelompokkan menjadi pendapatan dari usahatani, non usahatani, dan luar sektor pertanian seperti buruh industri, pengrajin, berdagang dan sebagainya. Pendapatan petani kelapa dalam selain bersumber dari usahatani kelapa dalam, juga berasal dari pendapatan usahatani di luar kelapa
Berdasarkan uraian dan latar belakang di atas, maka rumusan masalah dalam penelitian ini adalah: "Bagaimana pendapatan dan Kelayakan Usaha Jelli Kelapa pada UMKM Dekla di Desa Solo Bangkinang Kabupaten Kampar

Menurut Sadono Sukirno (2009:85) dalam teori ekonomi mikro, bahwa pendapatan adalah perolehan yang berasal dari biaya-biaya factor produksi atau jasa-jasa produktif. Pengertian tersebut menunjukan bahwa pendapatan 
adalah seluruh perolehan baik yang berasal dari biaaya faktor produksi maupun total output yang dihasilkan untuk seluruh produksi dalam suatu perekonomian dalam jangka waktu tertentu.

Tujuan menganalisis aspek finansial dari analisis kelayakan usaha untuk menentukan rencana investasi melalui perhitungan biaya dan manfaat yang diharapkan dengan membandingkan pengeluaran dan pendapatan, seperti ketersediaan dana, biaya modal, kemampuan usaha untuk membayar kembali dana tersebut dalam jangka waktu yang telah ditentukan dan menilai apakah usaha akan dapat dikembangkan terus (Dally 2016).

Kriteria Penilian Kelayakan Usaha bagi UMKM antara lain dilihat dari Payback periode (PP). Payback periode merupakan teknik penilaian terhadap jangka waktu (periode) pengembalian investasi suatu proyek atau usaha, perhitungan ini dapat dilihat dari perhitungan kas bersih merupakan penjumlahan laba setelah pajak ditambah dengan penyusutan. Kelemahan metode payback periode (PP) adalah a. mengabaikan perhitungan nilai waktu uang (time value of maney), b. tidak mempertimbangkan aruskas yang terjadi setelah masa pengembalian. 2. Average Rate of Return (ARR) marupakan cara untuk mengukur rata-rata pengebalian bunga dengan cara membandingkan antara rata-rata laba sebelum pajak (EAT) dengan rata-rata investasi

$$
\mathrm{ARR}=\frac{(\text { Rata-rata (average earning after tax) }}{\text { Rata-rata Investasi (Average Invesment) }}
$$

Net present Value (NPV)

Net present Value (NPV) atau nilai bersih sekarang merupakan perbandingan antara PV kas bersih (PV Proceed)dengan PV Investasi (Capital Out Lay) selama umur investasi, selisih antara nilai kedua PV tersebutlah yang kita kenal dengan (Net Present Value ) Untuk menghitung NPV terlebih dahulu kita harus tahu berapa PV kas bersihnya Pv kas bersih dapat dicari dengan cara mambuat dan menghitung dari cash flow perusahaan umur investasi tertentu

$$
\text { Net Present Value }(\mathrm{NPV})=\sum_{t=0}^{n} \frac{A t}{(1+k)^{t}}
$$

\section{Internal Rate Of Return (IRR)}

Internal Rate Of Return (IRR) merupakan alat untuk mengukur tingkat pengembalian hasil intern yatu dengan menggunakan rumus

$$
\begin{aligned}
& \mathrm{IRR}=i_{1}+\frac{N P V_{1}}{N P V_{1}-N P V_{2}}\left(i_{2}-i_{1}\right) \\
& \text { Kelayakan } \quad \text { usaha }
\end{aligned}
$$
didefinisikan sebagai kemampuan usaha untuk memberikan keuntungan bagi perusahan, ditunjukkan dengan Cash Flow yang positif, Payback Period lebih kecil dari umur investasi, $A R R$ lebih besar dari bunga investasi, $N P V$ bernilai positif, $I R R$ lebih besar dari bunga investasi, dan Profitabilty Index lebih besar dari 1. Pengukuran variabel menggunakan skala rasio (Billy Firman 2014)

Tujuan dari penelitian ini untuk mengetahui dan menganalisa pendapatan usaha Jelli kelapa yang diperoleh dari UMKM Dekla di Desa Salo bangkinang kabupaten Kampar, dan juga Untuk menganalisis Kelayakan Finansial usaha Jelli Kelapa di UMKM Dekla di Desa salo bangkinang Kabupaten Kampar.

\section{METODE}

Penelitian ini menggunakan metode deskriptif dengan pendekatan survey, menggunakan data sekunder dan data primer dari responden terhadap objekobjek yang ditanyakan sesuai permasalahan dan tujuan yang ingin dijawab, dan data yang ada yang tersedia di UMKM Dekla di desa Salo bangkinang Kabupaten Kampar,

Penelitian ini dilaksanakan di UMKM Dekla di desa Salo bangkinang kabupaten kampar Populasi dan sampel dalam penelitian ini adalah laporan keuangan dan Informasi dari Pimpinan dan karyawan di UMKM Dekla di Desa Salo Bankinang Kabupaten Kampar berjumlah sebanyak 6 orang 
Teknik pengumpulan data penulis melakukan wawancara langsung yaitu Tanya jawab dengan pemilik yang berwenang dalam memberikan informasi data yang diperlukan. Studi kepustakaan yang tujuaanya untuk menambah wawasan dan menambah bahan literature dan yang dapat menunjang penelitian ini

Analisa data yang digunakan dalam penelitian ini adalah dengan menggunakan metode deskriptif kwalitatif yang artinya setelah data diperoleh lalu dikelompokkan , dianalisa hubungan-hubungannya sehingga dapat diinterprestasikan dengan menggunakan teori-teori yang berhubungan sehingga dapat dijawab permasalahan yang dihadapi perusahaan tersebut. hal tersebut dapat dirumuskan sebagai berikut:

Analisis pendapatan menggunakan rumus : $\quad \boldsymbol{\pi}=\mathbf{T R}-\mathbf{T C}$

keterangan

$\pi \quad=$ Pendapatan

$\mathrm{TR}=$ Total Revanue

$\mathrm{TC}=$ Total Cost

Dimana $\mathrm{TR}=\mathrm{P} . \mathrm{Q}$

$\mathrm{TC}=\mathrm{FC}+\mathrm{VC}$

Sedangkan untuk mnegukur kelayakan Finansial menggunakan metode kriteria investasi yaitu a. Payback period (PP) b. Net Present Value (NPV) c. Average Rate of Return (ARR) d. Internal Rate Of Retun (IRR)

\section{HASIL}

Penerimaan UMKM Dekla adalah perkalian antara hasil produksi yang diperoleh dikali dengan harga jual dikurangai dengan baiaya Variabel ditambah dengan biaya tetap untuk lebih jelas dapat dilihat sebagai table berikut ini

Analisis pendapatan menggunakan rumus : $\quad \boldsymbol{\pi}=\mathbf{T R}-\mathbf{T C}$

keterangan

$$
\begin{aligned}
& \pi=\text { Pendapatan } \\
& \mathrm{TR}=\text { Total Revanue } \\
& \mathrm{TC}=\text { Total Cost } \\
& \text { Dimana } \mathrm{TR}=\mathrm{P} \cdot \mathrm{Q} \\
& \mathrm{TC}=\mathrm{FC}+\mathrm{VC}
\end{aligned}
$$

Tabel 1: Tabel Pendapatan UMKM Dekla

\begin{tabular}{|l|l|l|l|}
\hline Tahun & $\begin{array}{l}\text { Total } \\
\text { Revanue }\end{array}$ & Total Cost & Pendapatan \\
\hline 2014 & 432.000 .000 & 334.586 .600 & $97.413 .400,-$ \\
\hline 2015 & 604.800 .000 & 421.918 .280 & 191.881 .720 \\
\hline 2016 & 794.000 .000 & 504.926 .696 & 289.073 .304 \\
\hline 2017 & 734.360 .000 & 550.218 .040 & 184.141 .960 \\
\hline 2018 & 704.040 .000 & 490.101 .817 & 213.938 .183 \\
\hline
\end{tabular}

Sumber: Data Olahan UMKM Dekla 2019

Pendapatan yang di peroleh dari UMKM Dekla diperoleh dari total revenue di kurangi total cost, (terdiri biaya variabel ditambah dengan biaya tetap + pajak sebesar $15 \%$ ) tahun 2014 pendapatan yang diperoleh sebesar Rp 97.413.400,sedangkan tahun 2015 pendapatan atau keuntungan yang diperoleh senilai $\mathrm{Rp}$ 191.881.720, tahun 2016 pendapatan senilai Rp 289.073.304, tahun 2017 pedapatan diperoleh senilai Rp 184.141.960 sedangkan untuk tahun 2018 kkeuntungan di peroleh senilai $\operatorname{Rp} 213.938 .183$

Untuk mnegukur kelayakan Finansial menggunakan metode kriteria investasi yaitu a. Payback period (PP) b. Net Present Value (NPV) c. Average Rate of Return (ARR) d. Internal Rate Of Retun (IRR)

Payback period (PP)

Capital Out Lay

Proceed 1

Rp $\quad 677.800 .000$

Sisa

Proceed II Rp $\quad 165.193 .400$

Sisa

512.606 .600

\begin{tabular}{ll}
$\mathrm{Rp} \quad 259.661 .720$ \\
\hline
\end{tabular}

Rp 252.944 .880

Payback period (PP) 2 tahun $\underline{252.944 .880 \quad X \quad 100 \%} 0,70$ ( 8 bulan, 12 hari) 356.853 .304

Investasi kembali selama 2,70 tahun

\begin{tabular}{|c|c|c|c|}
\hline Tahun & Proceed & Df $15 \%$ & PV pada DF $15 \%$ \\
\hline 2014 & 165.193 .400 & 0,870 & 143.718 .258 \\
\hline 2015 & 259.661 .720 & 0,756 & 196.304 .260 \\
\hline 2016 & 356.853 .304 & 0,657 & $234,452,620$ \\
\hline 2017 & 251.921 .960 & 0,572 & 144.099 .361 \\
\hline 2018 & 306.718 .183 & 0,497 & $152,438,937$ \\
\hline \multicolumn{3}{|l|}{ jumlah } & $\frac{871.013 .436}{\frac{677.800 .000}{193.213 .436}}$ \\
\hline
\end{tabular}

Atau 2 tahun, 08 bulan, 12 hari Investasi dapat dapat diterima karna lebih cepat dari perkiraan yaitu selama 5 tahun

Net Present Value (NPV)

Sumber: Data olahan 2019

p.ISSN: $2407-800 \mathrm{X}$

e.ISSN: $2541-4356$ 
Dari hasil penelitian Investasi dapat diterima, karna npv menghasilkan nilai positif sebesar Rp 193.213.436

Average Rate of Return (ARR) marupakan cara untuk mengukur rata-rata pengebalian bunga dengan cara membandingkan antara rata-rata laba sebelum pajak (EAT) dengan rata-rata investasi

$\mathrm{ARR}=\frac{\text { (Rata-rata (average earning after tax) }}{\text { Rata-rata Investasi (Average Invesment) }}$

$(97.413 .400+191.881 .720+289.073 .304+184.141 .960+213.938 .183): 5$ $\mathrm{ARR}=-(677.800 .000+25.000 .000): 2$

$\mathrm{ARR}=\frac{195.289 .971}{-351.400 .000} \times \mathbf{x} 100 \%=55,6 \%$

Investasi dapat diterima karna hasilnya > besar dari tingkat keuntungan yang disyaratkan sebesar $15 \%$

Internal Rate Of Retun (IRR)

\begin{tabular}{|l|l|l|l|}
\hline Tahun & Proceed & Df 30 \% & PV pada DF 30\% \\
\hline 2014 & 165.193 .400 & 0,769 & 127.033 .725 \\
\hline 2015 & 259.661 .720 & 0,592 & 153.719 .738 \\
\hline 2016 & 356.853 .304 & 0,455 & 162.368 .253 \\
\hline 2017 & 251.921 .960 & 0,350 & 88.172 .686 \\
\hline 2018 & 306.718 .183 & 0,269 & 82.507 .191 \\
\hline jumlah & & $\underline{613.801 .593}$ \\
& & $\underline{677.800 .000}$ \\
& & & \\
\hline
\end{tabular}

Investasi dapat diterima, karna npv menghasilkan nilai positif $\mathrm{IRR}=i_{1}+\frac{N P V_{1}}{N P V_{1}-N P V_{2}}\left(i_{2}-i_{1}\right)$

$\mathrm{IRR}=15 \%+\frac{193.213 .436}{-\mathrm{N} / \mathrm{N} .213 .436-63.998 .407}(30 \%-15 \%)$

$\operatorname{IRR}=15 \%+\quad \frac{28.982 .015,4}{257.211 .843}(11,27 \%)$

IRR $=15 \%+11,26 \%=26,27 \%$

Hasil perhitungan dengan menggunakan internal Rate of Return, Nilai IRR diperoleh sebesar 26,27\% lebih besar dari tingkat keuntungan yang disyaratkan sebesar $15 \%$ maka IRR dapat diterima

\section{PEMBAHASAN}

Penelitian ini bertujuan untuk melihat Pendapatan dan kelayakan finansial yang ditanamkan di UMKM Dekla, Data penelitian diamabil selama lima tahun 2015 sampai dengan tahun 2018 dilihat dari pendapatan dengan menggunakan rumus keuntungan itu didapat dari total pendapatan dikurangi dengan total biaya ( $\boldsymbol{\pi}$ $=\mathbf{T R}-\mathbf{T C}$ )

1. Setiap tahunnya mendapat keuntungan untuk jangka selama 5 tahun tahun 2014 mendapat keuntungan sebesar $\mathrm{Rp}$ 97.413.400, sedangkan tahun 2015 sebesar Rp 191.881.720.untuk tahun 2016 mendapat keuntugan senilai Rp 289.073.304 dan tahun 2017 memperoleh keuntungan sebesar Rp 184.141.960 dan tahun 2018 senillai Rp 213.938.183

2 Dilihat dari kelayakan dengan menggunakan kriteria penilaian investasi

a. Metode Payback period Menunjukkan bahwa waktu yang diperlukan untuk menutupi investasi sebesar $\mathrm{Rp}$ 677.800.000 Investasi kembali selama 2,70 tahun Atau 2 tahun, 08 bulan, 12 hari

b. Metode Net present Value (NPV) Dari hasil penelitian Investasi dapat diterima, karna npv menghasilkan nilai positif sebesar Rp 193.213.436

c. Metode ARR (Average Rate of Return) menunjukkan bahwa tingkat keuntungan yang diperoleh rata-rata sebesar 55,60\% Investasi dapat diterima karna hasilnya > besar dari tingkat keuntungan yang disyaratkan sebesar 15

d. Metode (Internal Rate Of Return) perhitungan dengan IRR sebesar 19,48\% tingkat keuntungan yang disyaratkan lebih besar dari tingkat discount rate yang ditentukan maka investasi yang ditanamkan dapat diterima (Layak) yang mana IRR > $15 \% \%$ berarti Usaha ini dapat diterima dari kesimpulan dari beberapa metode yang digunakan bahwa investasi UMKM Dekla dapat diterima, atau layak untuk dilanjutkan atau untuk dikembangkan

Berdasarkan penelitian yang telah dilaksanakan dapat direkomendasikan pada UMKM Dekla Didesa Salo Bangkinang kabupaten Kampar, bahwa usaha yang dijalankan tersebut layak untuk dilaksanakan dan untuk dikembangkan sesuai dengan rencana yang diinginkan. Untuk UMKM Dekla untuk dapat 
meningkatkan hasil produksi serta mempertahankan pelanggan yang sudah ada, bahkan meningkatkannya, serta lebih memperhatikan biaya yang lebih effisien yang akan dikeluarkan agar keuntungan Usaha lebih Maksimal.

\section{SIMPULAN}

Dari hasil penelitian tersebut, maka dapat disimpulkan bahwa ssaha Jelli kelapa merupakan usaha yang bisa dipertimbangkan karena usaha ini merupakan kumpulan perusahaan sejenis dan dapat menciptakan nilai tambah guna menyerap tenaga kerja, Hasil penelitian mengenai pendapatan dan kelayakan usaha jelli kelapa ditinjau dari aspek financial dengan metode . Payback period (PP) investasi diterima karna sudah kembali 2 tahun, 08 bulan, 12 hari leboh pendek dari yang diperkirakkan. Metode Net Present Value (NPV) penelitian Investasi dapat diterima, karna npv menghasilkan nilai positif sebesar Rp 193.213.436 d. Internal Rate Of Retun (IRR) Nilai IRR diperoleh sebesar 26,27\% lebih besar dari tingkat keuntungan yang disyaratkan sebesar $15 \%$ maka IRR dapat diterima.

\section{DAFTAR RUJUKAN}

Allorerung, D., Z. Mahmud, A. Wahyudi, GS. Hardono, H. Novarianto, dan HT.Luntungan. 2005. Prospek dan Arah Pengembangan Agribisnis Kelapa. Badan Penelitian dan Pengembangan Pertanian Departemen Pertanian. Jakarta.

Billy Firman Manope, Paulus Kindangen, Hendra Tawas "Analisis kelayakan Usaha Komoditas Biji dan fuli Pala melalui penilaian asfek finansial pada pedagang pengumpul " Kios Chandra" dipulau Siau, Jurnal EMBA Vol 2 No 4 Desember 2014 Hal 320 - 330 ISSN 2303 - 1174

Dally Darmaseptana, Alex Saleh, Dwi Kurniawan Analisis Kelayakan Usaha Pengollahan Susu sapi Murni di Kota Bandung Reka Integra ISSN: 2338-5081 Jurnal Online
Institut Teknologi Nasional No 1 Vol 4 Januari 2016

Darmanto, 2013. Analisis Biaya dan Pendapatan Usaha Tani Kelapa Dalam Di Desa Jatimulya Wonosari. Journl. Uversitas Gajah mada, Yogyakarta. I (3) : 1-7

Hasyim, A.I., 2012. Tataniaga Pertanian. Diktat Kuliah. Fakultas Pertanian/Universitas Lampung.

Juliani Marwati dan M,W R, Fahriansyah 2011 Studi Variasi Konsentrasi Ektra Rosela(Hibicus sabdariffa L) dan keragenan terhadap mutu minuman Jeli rosella, jurnal,jurnal teknologi Pertanian 7 (1):1-8

Jakfar dan kasmir (2010) Studi kelayakan bisnis, Penerbit kencana prenada media Group Jakarta

Kasmir dan Jakfar., (2009), Studi Kelayakan Bisnis, Edisi Kedua, Penerbit Kencana Prenada Media Grup Jakarta

Nitisemito, Alex S,Umar burhan, Wawasan Studi kelayakan dan evaluasi Proyek, Bumi Aksara Jakarta 2009

Tri Yanto 2014 Pengembangan Kewirausahaan Jelly Drink Basis Nira Kelapa: Solusi Lapangan kerja di kecamatan Kutasari Purbalingga, Prosiding ISBN 978602-14930-3-8

Rudi. 2012. Analisis Usahatani dan Pemasaran Buah - Buahan Unggulan di Kabupaten serang .Jurnal Jurusan Ilmu - Ilmu Sosial Ekonomi Pertanian. FakultasPertanian. IPB. Bogor. III (4) : 1-9

Shantybio, 2006. Nata De Coco Yang Kaya Serat Biology Mikrobiologi.

http:// Transdigit.com. 